\title{
LA ECONOMÍA Y LA GUERRA
}

\section{Carlos Barciela}

El objetivo de este trabajo es el de arrojar alguna luz a dos problemas: el de las destrucciones originadas por la Guerra Civil y el del ritmo de la recuperación posbélica. Para centrar la cuestión partiré, primero, de unas someras consideraciones sobre la importancia de los problemas económicos en el desencadenamiento del conflicto $y$, segundo, de una valoración del impacto económico de la guerra.

En lo que concierne a la primera de las cuestiones, se puede sostener que la guerra no estuvo provocada, esencialmente, por motivos económicos. Es cierto que en 1929, en vísperas de la Gran Depresión, España no formaba parte del grupo de países desarrollados y que mantenía algunos rasgos y características de los países atrasados. Sin embargo, nuestro país había conocido, desde comienzos del siglo, un importante proceso de progreso económico y social. El avance, lento pero sostenido, en la agricultura; el éxito en la incorporación de las nuevas tecnologías propias de la segunda industrialización; la modernización del sector terciario y de la Administración pública; el progreso de la urbanización; el aumento del nivel educativo de los españoles y la paulatina apertura al exterior, se tradujo en un crecimiento económico sostenido y mayor que el experimentado por los países europeos en su conjunto. Incluso en el campo, símbolo para muchos del secular atraso español, donde las condiciones de vida eran más difíciles para la mayor parte de sus habitantes, se vivió una época de relativa tranquilidad y de paz social, manifestación de que las citadas condiciones de vida eran, a pesar de todo, «soportables». El efecto conjunto de la Gran Depresión y de la incertidumbre generada por la llegada de la República, con ser estimables, -podemos hablar de un estancamiento económico entre 1929 y 1935-, no fue catastrófico, especialmente si lo comparamos con lo acontecido en otros países europeos, duramente castigados por la recesión y el 
paro. Además, la República puso en marcha programas económicos destinados a paliar los peores efectos de la crisis. En definitiva, España no era un país en el que existiera un grave malestar social, de origen económico, capaz de provocar una «rebelión de la pobreza».

Sin embargo, otro tipo de cuestiones económicas y, particularmente, la desigual distribución de la propiedad agraria, sí que fueron un factor crucial en el desencadenamiento del conflicto. Con el advenimiento de la República resurgieron con fuerza las arraigadas y centenarias aspiraciones de los desposeídos a la propiedad de la tierra, a lograr el tan soñado «reparto». De manera paralela, los propietarios agrarios y sus organizaciones representativas, gremiales y políticas, se fueron enrocando en posiciones radicalmente inmovilistas, cerrando el camino a cualquier posibilidad de lograr una reforma agraria moderada y pactada. $\mathrm{Ni}$ siquiera aceptaron propuestas tan tibias como las propugnadas por la derecha democristiana ${ }^{1}$. En consecuencia, y como es bien sabido, las posturas se fueron radicalizando, ofreciendo tintes cada vez más violentos. Que el mantenimiento de la distribución de la propiedad de la tierra fue causa directa de la guerra lo han sostenido muchos historiadores, aunque tiene especial interés la claridad meridiana con que lo hizo en 1943, Ángel Zorrilla Dorronsoro, ingeniero agrónomo, falangista de la vieja guardia, amigo de José Antonio Primo de Rivera, responsable del Servicio Nacional de Reforma Económica y Social de la Tierra (SNREST) durante la guerra, y primer director del Instituto Nacional de Colonización ${ }^{2}$. Igualmente, con la República, y especialmente tras la victoria del Frente Popular, se radicalizaron las posturas de los grupos políticos y organizaciones sindicales que propugnaban la eliminación del sistema económico capitalista. También en este caso, la reacción de las clases burguesas, que inicialmente no habían cuestionado la República -excepción hecha de la nobleza y un sector de grandes empresarios monárquicos-, fue la de distanciarse de un régimen que consideraban incapaz de mantener el orden y de defender el estatus establecido. En definitiva, la reacción ante el cuestionamiento del sistema económico y de manera especial de la distribución de la propiedad agraria, más que las condicio-

1. El mejor representante, desde el punto de vista doctrinal, de esta posición es Severino Aznar. Desde un punto de vista político lo es Manuel Giménez Fernández, catedrático de la Universidad de Sevilla y ministro de agricultura de la CEDA. Sobre estas cuestiones puede verse BARCIELA (2004).

2. En la reunión del Consejo Nacional de Colonización celebrada en Madrid los días 29 y 30 de noviembre de 1943, afirmaba Ángel Zorrilla: «La diferencia de posiciones (en materia de reforma agraria) se fue señalando más y más a lo largo del Movimiento Nacional en una y otra zona, pues, efectivamente, las armas se habían tomado, entre otras cosas, para defender una y otra posición frente a estas cuestiones de modo muy palpable en lo que se refiere al concepto de propiedad de la tierra». Para más detalles, BARCIELA (1986). 
nes de vida de las clases trabajadoras, forman parte del conjunto de causas que provocaron el golpe militar y, tras su fracaso, la Guerra Civil ${ }^{3}$.

Las actuales investigaciones han reafirmado la idea de que las fuerzas económicas fueron un factor decisivo en la victoria final de los sublevados. La guerra, aunque presente rasgos de heroísmo, de idealismo y de individualismo «decimonónicos», -como el surgimiento de grandes líderes militares de extracción popular-, que han llevado a presentarla como la última guerra «romántica», fue, en realidad, una guerra moderna en la que se movilizaron cuantiosísimos recursos humanos y materiales, que exigieron un ingente esfuerzo económico ${ }^{4}$. Los frentes de batalla constituían el último y definitivo acto de la larga secuencia de actividades destinadas a la preparación de grandes maquinarias bélicas, alimentadas con un incesante flujo de dinero.

La Guerra Civil se desarrolló, evidentemente, en territorio español y la inmensa mayor parte de sus víctimas fueron españolas. Sin embargo, sus designios y su resultado final se decidieron en el tablero internacional. Era impensable que, en pleno siglo XX, una guerra en la Península Ibérica se contemplara por las principales potencias europeas como un conflicto interno. En este sentido, conviene insistir en lo inadecuado de los análisis sobre las fuerzas relativas de los bandos en guerra, circunscritos exclusivamente al ámbito español. Se suelen presentar, muchas veces, balances en los que, al parecer, tras el fracaso inicial del golpe militar, todo era favorable al Gobierno legal: mayor extensión territorial, mayoría de la población, las principales ciudades, las zonas agrícolas más prósperas y avanzadas, las mejores reservas mineras (exceptuando las piritas de Huelva), las regiones más industrializadas, las reservas metálicas del Banco de España, el control de las instituciones, la legitimidad internacional... Este planteamiento se completa, de forma oportunista, por parte de la historiografía franquista, con un corolario glorioso: a pesar de su neta superioridad, la República se hundió víctima de sus propios errores y excesos, ante los elevados fines del alzamiento. Sin embargo, este análisis de las fuerzas en juego, limitado a los recursos internos de cada zona, es totalmente insatisfactorio por falta de realismo. Debemos recordar que el conflicto español se internacionalizó inmediatamente, aunque es más adecuado afirmar que ya se había internacionalizado en su fase preparatoria y conspirativa ${ }^{5}$. Los poderosos grupos económicos españoles con-

3. Sobre los orígenes de la guerra puede verse Julí́ (2008).

4. Aunque supongo que no con la precisión de un analista militar, Pío Baroja expresa muy bien, con su característico estilo y su vena antimilitarista, las diferencias entre las guerras del siglo XIX y la Primera Guerra Mundial, en el capítulo «El prestigio de los militares», BAROJA (1917).

5. Moradiellos (2008). 
trarios a la República y partidarios del golpe militar, -la trama civil del golpe-, aprovecharon el rechazo que el régimen republicano provocaba en los medios conservadores europeos, especialmente con la agitación que se vivió tras las elecciones de febrero de 1936, para allanar el camino en la relación de los militares golpistas con los medios financieros europeos y con las fuerzas políticas conservadoras de los principales países occidentales. En esta línea son ejemplares, y bien conocidas, las decisivas maniobras conspirativas y los recursos financieros puestos a disposición de los sublevados por J. March, en colaboración con la banca británica ${ }^{6}$.

En las primeras y decisivas semanas del conflicto, el panorama internacional se clarificó, rápida y plenamente, en favor de los sublevados. La «no intervención» pactada por las potencias democráticas europeas, que implicaba el bloqueo en el suministro de armas a la República, fue un golpe decisivo para la supervivencia del sistema democrático en España. A partir de entonces, la ayuda recibida por la República quedó limitada a la proporcionada por México y por la URSS. El apoyo de México, fraternal y desinteresado, tuvo un alcance muy limitado en su cuantía y composición, en relación a las exigencias del conflicto. La ayuda soviética merece algunos comentarios. En primer lugar, se recibió tardíamente (los primeros suministros no llegaron a España hasta octubre de 1936 y estaban formados por armas ligeras de escaso valor estratégico). Parece que Stalin esperó para proporcionar su apoyo hasta comprobar que la República resistía el inicial envite de los golpistas y hasta que obtuvo garantías sólidas de pago. Para entonces, en el plano militar y en la ocupación territorial, los sublevados habían conseguido objetivos decisivos. En segundo lugar, es necesario revisar el propio término de ayuda. Lo que la URSS hizo con la República fue un conjunto de operaciones comerciales de venta de armas, no siempre de la mejor calidad, ni las más modernas de la época, cobradas al contado, con la garantía anticipada de 510 toneladas de oro (la mayor parte de las reservas metálicas del Banco de España), a precios excesivos y jugando, siempre a su favor, con la falta de transparencia del tipo de cambio del rublo. Stalin se comportó como un monopolista de libro, sacando todos los beneficios que la situación le ofrecía ${ }^{7}$. Además de las armas, la URSS vendió a la República petróleo, materias primas (principalmente algodón), alimentos y medios de transporte, y compró algunos productos españoles como frutas. Todo apunta a que, también en estos intercambios, la URSS salió muy beneficiada ${ }^{8}$. Finalmente, hay que señalar que

6. Torres Villanueva (2006)

7. Pablo Martín Aceña (2001) y (2006). Ángel Viñas (2006) y (2007) ha estudiado con detalle las dificultades sufridas por la República.

8. Elena Martínez (2006b). 
la ayuda soviética finalizó casi tan pronto como se agotaron las reservas de oro, si bien es cierto que para entonces la suerte de la guerra estaba decidida ${ }^{9}$. Se puede también hacer una reflexión sobre si la URSS habría podido hacer algo más para facilitar la salida de España de tantos republicanos que quedaron a merced de la represión de los vencedores. En definitiva, a pesar de sus importantes recursos líquidos, la República sólo pudo contar con un único suministrador de armas, que aprovechó su privilegiada posición.

Al margen de los gobiernos que adoptaron posiciones definidas en la guerra, se produjo otro tipo de intervención internacional de carácter privado. Los medios financieros y las grandes empresas mundiales también tomaron parte a favor de alguno de los bandos en conflicto. En lo que concierne a las finanzas europeas, la República española, la República de «trabajadores», era un régimen indeseable e insolvente. El bando nacional, sin embargo, podía presentar ante los selectos círculos financieros e industriales europeos a la flor y nata de la alta nobleza y a los más destacados banqueros y hombres de empresa españoles, con todas sus redes de influencias. La legitimidad del Gobierno republicano era un valor escasamente cotizado en esos ambientes.

Por su parte, las grandes empresas, particularmente las norteamericanas, se volcaron en su apoyo a Franco y ayudaron (en este caso sí vale el concepto), de manera decisiva a los sublevados, mediante la entrega a crédito de ingentes cantidades de combustible y de medios militares de transporte. Es muy conocido el caso de la petrolera TEXACO que rompió unilateralmente sus compromisos con la República y se puso al servicio incondicional de Franco. Al igual que esta petrolera, grandes empresas automovilísticas suministraron a los rebeldes importantes cantidades de camiones y vehículos militares desde los primeros días de la guerra, vía Lisboa, como en el caso de la General Motors y sus camiones Chevrolet $^{10}$.

Vistas así las cosas, en el plano internacional, el único en el que es posible hacer un análisis realista, la inicial y teórica ventaja de la República resulta ser un espejismo. Iniciada la guerra, lo que contaba de verdad no era una genérica superioridad del PIB republicano frente al nacional. Lo único que contaba era la capacidad de poner en el campo de batalla, lo más rápidamente posible y

9. Agotada la ayuda respaldada con las reservas, la URSS concedió dos créditos a la República.

10. Como en los primeros momentos de la guerra fue necesario cubrir las apariencias, la General Motors descargó sus envíos de camiones Chevrolet a los sublevados en el puerto de Lisboa. Con el beneplácito de Salazar, militares españoles se trasladaron a la capital portuguesa y desde allí condujeron los camiones a la España sublevada por la frontera de Salamanca. 
antes que el enemigo, un ejército entrenado y equipado. La ventaja industrial de la República, en ausencia de un moderno sector de industrias militares, era, en este sentido, irrelevante. En julio de 1936 lo decisivo no era la producción de lingotes de hierro o de carbón. Lo decisivo era disponer de una moderna fuerza aérea y naval, capaz de haber impedido el paso del estrecho y de haber bloqueado a los rebeldes en Marruecos y en Sevilla. Tampoco la leve superioridad demográfica tenía, en esos días decisivos, el más mínimo valor. Lo que importaba era disponer de hombres integrados en fuerzas de choque entrenadas y con experiencia bélica. En este sentido, la República se encontró en una situación de evidente y decisiva inferioridad. La zona ocupada por los rebeldes carecía de industria y contaba con una población inferior, pero tenían sobre el terreno tropas bien armadas y entrenadas ${ }^{11}$. La República se encontró, por el contrario, con un ejército en buena medida descabezado, desorganizado y marcado por la sospecha sobre la sinceridad de su lealtad. La entrega de armas a las organizaciones de izquierdas, decisiva para el fracaso del golpe en muchas grandes ciudades, tuvo también efectos perniciosos: persecución y eliminación de muchos mandos sospechosos, en ocasiones con poco fundamento; organización de dispersas milicias populares con obediencia propia, escasa disciplina y nula eficacia militar; tremenda descoordinación y necesidad de tiempo (un bien escasísimo en aquellos momentos) para preparar un ejército capaz de hacer frente de forma eficaz al ejército franquista.

Hay un aspecto de la superioridad inicial de la República en el que se ha insistido mucho, que ciertamente es incuestionable y que, sin embargo, muestra también de manera clara cómo una teórica ventaja inicial podía resultar, en la práctica, poco decisiva. Me refiero a las reservas de metales preciosos del Banco de España, unas 710 toneladas de oro, cantidad verdaderamente fabulosa ${ }^{12}$. Pues bien, al igual que señalábamos con la industria, también en el caso del oro se comprueba que la enorme ventaja de la República quedaba enormemente limitada en la práctica. El Gobierno legítimo necesitaba en julio de 1936, de manera apremiante, armamento moderno (especialmente aviones, barcos y armamento pesado) para frenar la sublevación antes de que se consolidara y tomara posiciones decisivas en la península. El oro era un medio perfecto, en principio, para adquirir las divisas con las que obtener dichos equipamientos. Sin embargo, la República, como consecuencia de su débil posición internacional, se encontró con un sinfín de trabas e impedimentos para conseguirlos. Perdió un tiempo,

11. Contaron, incluso, con la ventaja de controlar un sector industrial de gran importancia militar, como era el de la industria conservera gallega, riojana y navarra, del que salieron suministros vitales para las tropas.

12. Sobre el papel del Banco de España, Martín Aceña (2008). 
estrictamente vital, en buscar proveedores y, tras sucesivos fracasos, quedó en las manos exclusivas de la URSS. Para la suerte de la guerra fue decisiva la actitud de Gran Bretaña y de Francia, países que sí que habrían podido, si hubiesen querido, proporcionar de forma inmediata material bélico para parar el golpe militar. Evidentemente, las simpatías de las democracias occidentales, especialmente de Gran Bretaña, no estaban por la República. Las dificultades y el tiempo que el Gobierno republicano tuvo que superar y emplear, nos permiten sostener que las reservas de oro, incluso su cuantía, tuvieron un relativo valor. Se podría afirmar que, si en lugar de 700, las reservas hubiesen sido de 1.000 toneladas, la situación real de indefensión de la República no habría cambiado. Todo lo más, la agonía se habría prolongado. Visto el desarrollo de los acontecimientos, lo mejor para el país habría sido que la República no hubiera tenido ninguna reserva de oro y que la guerra hubiese finalizado rápidamente.

Los sublevados, como ya hemos recordado, se consolidaron inicialmente en un territorio menor, con inferior población, agrícola y más atrasado, y con unos recursos financieros que no eran, ni remotamente, comparables a los del Banco de España. Sin embargo, contaron de manera inmediata y absolutamente comprometida, con la ayuda militar, económica y estratégica de las potencias fascistas, con los créditos de la banca y de las grandes empresas internacionales, y con las grandes fortunas españolas que les otorgaron una neta superioridad militar que era, en definitiva, de lo que se trataba.

Si el planteamiento que he realizado es correcto, en el sentido de que la suerte de la guerra se decidió en el tablero internacional, se debe admitir la conclusión de que lo acontecido con la economía de las zonas enfrentadas pierde algo de relevancia. Se convierte en un elemento explicativo importante, pero no decisivo. Existe una idea bastante generalizada de que la economía funcionó mejor en la zona sublevada que en la zona republicana. Esta impresión se deriva, más que de un análisis de los datos concretos (de los que carecemos en algunas ocasiones), de la distinta forma en la que se organizaron política y económicamente ambas zonas. Frente a la militarización, la disciplina y la unidad de mando que se impuso, en ocasiones por medio del terror, en la zona nacional, en la zona republicana se sufrió un proceso para el que se suelen utilizar expresiones como fragmentación, disgregación o disolución del poder. En una zona se impuso una disciplina favorecedora de la actividad económica y al servicio exclusivo de la victoria militar, mientras que en la otra se vivió un proceso de revolución social y tendencias territoriales centrífugas que, necesariamente, tuvieron que resultar negativos para el aparato productivo ${ }^{13}$. En efecto, el verano de 1936 fue caótico

13. La situación de los empresarios en Cabrera y Del Rey (2008). 
para la economía republicana. A los efectos dañinos propios de cualquier guerra, en los que no merece la pena detenerse, se sumaron los derivados de la puesta en marcha de las ideas y programas de los diversos y heterogéneos grupos que apoyaban a la República. Para muchos era la ocasión esperada de acabar revolucionariamente con el sistema económico capitalista; para otros, aún siendo ése el objetivo último, resultaba conveniente una alianza transitoria con las fuerzas burguesas republicanas hasta el final de la guerra; finalmente, los partidos moderados no querían ninguna revolución, ni durante ni después de la guerra. Por su parte, los grupos revolucionarios tenían ideas muy distintas, y radicalmente opuestas, sobre el carácter del sistema económico que tendría que imponerse de manera inmediata o en el futuro. Las discrepancias entre los anarquistas y los comunistas eran muy grandes y su enemistad, mitigada por la guerra, era profunda y manifiesta. Los propios anarquistas defendieron políticas distintas en diferentes regiones, y los comunistas, a su vez, estaban ferozmente enfrentados, entre la corriente dominante estalinista e integrada en la Tercera Internacional y partidos como el POUM de inspiración trotskista. Para todos estos grupos, sin excepción, la burguesía, sus representantes y sus «servidores» (entre los que colocaban a todos los altos técnicos, gerentes y directivos de las empresas) eran, por definición, enemigos de clase, por lo que sufrieron persecución y fueron, en el mejor de los casos, separados de sus cargos y depuestos ${ }^{14}$. Evidentemente, este tipo de actuaciones perjudicó la buena marcha de las empresas y de la Administración republicana, reafirmó el deseo de los indecisos de unirse a los sublevados, enriqueciendo sus filas con buenos técnicos y gestores ${ }^{15}$. El deseo de acabar con los valores burgueses, con la propiedad privada y con los mecanismos capitalistas de explotación de los trabajadores, desencadenó una ola de incautaciones y expropiaciones, y en los centros de trabajo se cuestionaron lo que se consideraba disciplina laboral burguesa y las jornadas y los salarios con los que se extraía la plusvalía a los trabajadores. La desorganización, la indisciplina, las subidas sala-

14. En estos dos últimos años he colaborado en la elaboración del Diccionario Biográfico Espanol de la RAH, para el que he escrito cerca de trescientas biografías de ingenieros agrónomos desde que se puso en marcha la Escuela en 1855 hasta los años cincuenta del siglo XX. He podido constatar como un significativo número de estos profesionales, algunos con destacadas trayectorias, fueron asesinados, especialmente en los primeros días del conflicto por grupos descontrolados.

15. En el trabajo citado en la nota anterior aparecen también un buen número de agrónomos que huyeron de la zona republicana y que prestaron sus servicios en el bando rebelde. Algunos casos significativos, entre otros muchos, son el de Cirilo Cánovas que llegó a ser ministro de Agricultura entre 1957 y 1965, o el de Ángel Zorrilla Dorronsoro que asumió la dirección del Servicio Nacional de Reforma Económica y Social de la Tierra en 1938 y del Instituto Nacional de Colonización en 1939. 
riales y la reducción de las jornadas de trabajo fueron las consecuencias de este movimiento revolucionario, nada favorables, ni en el plano económico ni en el militar, para el objetivo de ganar de guerra. Además del enfrentamiento de clases, la República sufrió, simultáneamente, un proceso de fragmentación territorial y sectorial de su autoridad. Por una parte, la división del territorio leal, debida a la guerra, favoreció la aparición de Consejos Regionales. Por otra, se produjo una tendencia a la reafirmación del poder de los gobiernos autonómicos y la aparición de organizaciones económicas (de empresas y sectores) controladas por los sindicatos. El ejemplo más llamativo lo constituye el comercio exterior, sector clave en una economía de guerra. La Generalitat catalana creó una institución propia, con representaciones oficiales en el exterior, para el control del comercio con el extranjero, y el CLUEA, creado por los sindicatos, se hizo con el control de las exportaciones de agrios en el Levante español. En algunos casos, verdaderas bandas de milicianos descontrolados se lanzaron a actuaciones directas de saqueo. Es innegable que este estado de cosas tuvo que reforzar la impresión negativa que los medios conservadores mundiales tenían sobre la autoridad de la República y debió introducir la duda entre los que tenían confianza.

Sólo a partir de septiembre de 1936, con los gobiernos de concentración, y con Negrín en Hacienda, se inició un lento, costoso e inconcluso proceso de reconstrucción de la autoridad del Estado. Se fueron creando diversos organismos, que tenían como objetivo el control de la actividad económica interna y de las relaciones económicas exteriores, con el objetivo de ganar la guerra. Este proceso, absolutamente necesario, tuvo que vencer fuertes resistencias y ocasionó graves enfrentamientos entre el Gobierno central y representantes de los gobiernos autonómicos y de las organizaciones sindicales que, en la situación que vivía la República, eran suicidas. El Gobierno sufrió un fuerte desgaste y tuvo que dedicar tiempo y energías absolutamente vitales, sencillamente para tratar de reafirmar su autoridad. Con las tropas franquistas presionando en todos los frentes, esta dispersión de esfuerzos resultó letal.

En la zona sublevada todas las energías se volcaron en el objetivo de ganar la guerra. Se adoptaron, sin discusión, todas las medidas que los mandos militares consideraron necesarias al objeto de movilizar los recursos económicos en aras de la victoria militar. En esta línea, se procedió a la militarización de la economía; se llevaron a cabo las incautaciones (empresas, materias primas, medios de transporte marítimos y terrestres) que se consideraron oportunas por la autoridad militar; se establecieron normas para la entrega de metales preciosos y valores extranjeros al objeto de ir creando un fondo de divisas; se fijaron cupos de entrega obligatoria y controles de precios, y se estableció un férreo control sobre el comercio exterior y la posesión de divisas por particulares. La peor parte, 
sin embargo, se la llevaron los trabajadores. Como declarados enemigos de clase de los sublevados, fueron despojados, inmediatamente, de todos sus derechos políticos y sindicales. Igualmente vieron recortados sus derechos económicos y laborales, concretamente los concernientes a las mejoras salariales y los relativos a la duración de la jornada de trabajo. Muchas de estas medidas permitían prever las futuras tendencias de la política autárquica e intervencionista que se consolidaría plenamente durante la posguerra ${ }^{16}$.

No disponemos de ningún método que nos permita valorar de manera precisa, numérica, el efecto beneficioso del entramado institucional centralizado y disciplinado creado en la España franquista, y el perjudicial causado por la fragmentación de la autoridad en la zona republicana. Nadie puede, lamentablemente, ofrecer unos guarismos que, al modo de una competición deportiva, muestren con precisión la diferencia entre los contendientes. Nos tenemos que conformar con las impresiones que nos proporciona la evidencia cualitativa, traducida en términos valorativos. Es incuestionable que la Primera Guerra Mundial -y en cierta medida la guerra de secesión norteamericana- había puesto de manifiesto que las guerras del siglo XX exigían una férrea organización económica, con la militarización de muchos ámbitos de la sociedad y con el total sometimiento de los intereses civiles a las exigencias militares, para la puesta en marcha de las poderosas maquinarias bélicas modernas y para disponer de mecanismos coercitivos capaces de imponer a la población sacrificios extremos. Si aceptamos la validez de estas experiencias, tenemos que admitir que el claro contraste organizativo entre las dos zonas, que se puso de manifiesto en numerosas ocasiones durante toda la guerra, debió tener efectos dañinos para el bando leal. Recordemos, por poner un ejemplo, dos hechos acaecidos en la primavera de 1937, separados por muy pocos días. En abril se publicaba en la zona nacional el Decreto de Unificación, por el que se creaba el partido único Falange Española Tradicionalista y de las JONS, a cuya cabeza se situaba el ya Jefe del Estado y Generalísimo de los Ejércitos. Franco lograba con esta norma la cuadratura del círculo. Una fuerza autoproclamada «revolucionaria», como Falange y las JONS, en cuyo programa económico aparecían vagas propuestas anticapitalistas y exigencias de una profunda renovación social y económica, se fusionaba, bajo el poder de un militar reaccionario, y sin mayores protestas, con las fuerzas más retrógradas y más inmovilistas del país, y aceptaban ser bautizadas con el apellido «tradicionalista». En la zona republicana, en el mes de mayo, sólo unos días más tarde, se enfrentaban a tiros en pleno centro de Barcelona milicias anarquistas y del POUM contra las restantes fuerzas del Frente Popular, acontecimientos que culminaron con el secuestro, tortura y asesinato, por parte de los

16. GÁLVEZ (2006). 
comunistas, del dirigente del POUM Andréu Nin. ¿Qué efectos tuvieron estos, y otros, enfrentamientos internos sobre la actividad económica republicana? Nos movemos en un terreno que Isaiah Berlin situaría, en mi opinión, en lo que denomina «conocimiento impreciso» ${ }^{17}$. No podemos traducir a cifras estos hechos. Con todo, racionalmente, tenemos que concluir que las consecuencias de estos distintos modelos, de la disciplina militar y la unidad de mando, frente a la disgregación del poder, tuvieron que ser necesariamente «importantes» en la actividad económica y en el curso del conflicto. Un gobierno democrático, especialmente en momentos de guerra, resulta mucho más costoso y difícil de gestionar que una dictadura. La República se encontró en la difícil situación de compaginar el respeto a las más avanzadas normas sociales y laborales, y a los compromisos constitucionales relativos a la existencia de poderes autonómicos -con los que estaba sinceramente comprometida- con la imperiosa necesidad de reforzar su propio poder, para hacer frente de manera eficaz a la guerra.

La información disponible sobre la marcha de la producción en la zona republicana muestra un razonable pulso económico, teniendo en cuenta el cúmulo de problemas a los que tuvo que hacer frente. La producción agraria, a pesar de las graves dificultades en el abastecimiento de diversos medios de producción, se mantuvo en niveles aceptables ${ }^{18}$. El sector industrial ha sido objeto de un detallado análisis por parte de J. Catalan que concluye con una visión bastante optimista, dentro de las circunstancias ${ }^{19}$. De hecho, este autor ha restado importancia a los posibles efectos negativos derivados de los problemas internos sufridos por la República y a los que nos referíamos anteriormente. Para Catalan, el progresivo declive industrial de la España leal se debió a factores fundamentalmente económicos, como la desarticulación de los flujos comerciales tradicionales, la falta de una amplia gama de suministros y la paulatina pérdida de mercados. Las evidencias aportadas por Catalan resultan muy atractivas, especialmente cuando muestra la sincronía entre las causas por él señaladas y el declive de la producción. Sin embargo, su planteamiento no es, en mi opinión, concluyente. Es razonable pensar que, en un ambiente de más estrecha cooperación entre todas las fuerzas antifascistas, la producción industrial se hubiera comportado todavía mejor de lo que lo hizo. En cualquier caso, la relativamente aceptable trayectoria de la producción de la zona republicana, no logró evitar el temprano desabastecimiento interior de la población y de la industria, ni el déficit comercial exterior.

17. BerLin (2004), especialmente los ensayos «La inevitabilidad histórica» y «El nacimiento del individualismo griego».

18. Barciela (1983), Elena Martínez (2006a).

19. Catalan (2006). 
La Hacienda republicana, con el oro en prenda para el pago de las armas, agotadas las vías impositivas y el recurso al endeudamiento interno, y cerradas las fuentes de crédito exterior, tuvo que financiarse mediante adelantos del Banco de España con el consiguiente aumento de la circulación monetaria y el paralelo proceso inflacionista ${ }^{20}$. El Tesoro republicano intentó, también, nutrirse con desesperadas medidas de emergencia: obligación de entrega de metales preciosos y joyas, requisas, incautaciones y creación de la Caja de Reparaciones por Daños y Perjuicios ${ }^{21}$. A pesar de esta aparente variedad de recursos, las fuentes casi exclusivas de financiación fueron las reservas y el recurso al Banco de España. Esta difícil situación se vio agravada por la disgregación territorial de la Hacienda y los problemas de descoordinación que, en el caso de los surgidos con la Hacienda vasca, alcanzaron niveles incomprensibles en una situación de guerra. Además del espectacular aumento de la cantidad de billetes del Banco de España, la República sufrió otra fuente de inflación monetaria originada por un variopinto conjunto de «entidades emisoras» públicas y privadas. Las razones de esta inflación de emisiones son muy variadas. Muchas de ellas fueron la respuesta a la falta de moneda fraccionaria derivada, a su vez, del atesoramiento y de la requisa de la plata y de los demás metales utilizados en la acuñación de monedas que, como el cobre, tenían usos militares alternativos. A estas causas responden las emisiones de billetes de baja denominación por entidades locales, cooperativas e, incluso, por comerciantes particulares. Las emisiones respondieron, en otros casos, al deseo de reafirmar la autonomía política de los gobiernos autónomos. Además, en algunas colectividades se intentó suprimir el dinero. Era ésta una vieja aspiración de los anarquistas que veían en el dinero una causa de las desigualdades sociales y lo sustituyeron por complejos sistemas de vales y, en ocasiones, por billetes con nuevas y revolucionarias denominaciones. El resultado fue un espectacular, colorido y multiforme proceso de emisiones que provocaron la total falta de unidad monetaria en la zona republicana y un descontrolado proceso inflacionista. A ello hay que añadir la eficaz guerra monetaria desencadenada por el bando nacional contra la moneda republicana ${ }^{22}$.

Para la zona sublevada, la información disponible sobre la marcha de la producción no es tan completa como la que tenemos para la zona republicana. Sí que sabemos que los problemas de desabastecimiento no fueron tan graves como los sufridos por la República. En buena parte, este fenómeno está ligado a la rápida recuperación de la producción agraria e industrial en las zonas ocu-

20. Sobre los problemas de las dos Haciendas: Comín y López (2002), Comín (2008), MartoReLl y Comín (2008) y Pons (2006).

21. Sánchez Recio (1991).

22. SÁnchez Asiaín (2008). 
padas, en las que se impuso un régimen de terror que forzó el ritmo de trabajo. También contribuyó a este buen comportamiento productivo la paulatina ampliación del mercado, las facilidades en el abastecimiento de materias primas y el crédito exterior. El aumento de la producción permitió el incremento de las exportaciones de materias primas (sobre todo minerales) y de alimentos, en particular hacia Alemania e Italia, de manera que el régimen de Franco empezó a pagar, ya durante el conflicto, la ayuda recibida de ambos países. La ayuda alemana, de una importancia estratégica fundamental, se articuló meticulosamente en un amplio proyecto de penetración y control de la economía española (en especial de los recursos minerales) por parte germana. La ayuda italiana, fue más importante cuantitativamente, más incondicional, más propia del carácter latino, más acorde con un personaje vanidoso y teatral como Mussolini. En relación al comercio exterior de la zona nacional, es de interés destacar un rasgo que se consolidará plenamente en la posguerra: la total supeditación de las necesidades de la población, incluidas las de alimentos básicos, a los fines industriales militares y autárquicos.

Los rebeldes carecían en principio, y como es sabido, de recursos financieros similares a los del Banco de España republicano. Esto, como ya hemos señalado, no supuso ningún contratiempo grave ante la facilidad con la que pudieron acceder a otras fuentes alternativas. En lo concerniente a las necesidades de medios de pago exteriores, pudieron contar con la ayuda de Alemania, Italia y Portugal, con las donaciones privadas (incluida la de Alfonso XIII) y con los créditos de empresas y bancos extranjeros. En total los sublevados contaron con un montante de financiación similar al volumen de las reservas del Banco de España a disposición de la República. En el plano interior, se nutrieron con anticipos procedentes del Banco de España fundado en Burgos y, en menor medida, con fondos recogidos por la suscripción nacional y con algunos recursos impositivos.

Al tratar del impacto económico de la guerra hay que distinguir, a mi entender, al menos dos tipos de consecuencias. Por una parte, se plantea el problema de valorar el coste económico del conflicto y, por otra, el de estimar sus efectos a corto, medio y largo plazo. Distinguir estas dos facetas es, a mi entender, absolutamente necesario en el caso de una guerra que, como en la española, estaban en juego, además de diferencias políticas e ideológicas, distintos modelos de organización económica. La victoria de los sublevados implicaba el triunfo de unos planteamientos económicos que cuestionaban, total o parcialmente, algunos de los principios fundamentales del sistema económico liberal-capitalista. Es precisamente en este sentido en el que entiendo que a la hora de valorar el impacto económico de la guerra no es posible separar el efecto directo del conflicto del derivado del carácter del régimen triunfante. Dicho de otra manera, 
el impacto económico de la guerra habría sido mucho más limitado si, tras la contienda, hubiese gobernado en España una coalición conservadora homologable y alineada con los países capitalistas occidentales. Valorar el coste directo de la guerra es una tarea, evidentemente, harto difícil. En algunos casos es posible realizar estimaciones precisas en términos cuantitativos y sus correspondientes equivalentes monetarios, como por ejemplo, en la destrucción de viviendas, infraestructuras y medios de transporte, y contamos al respecto con datos suficientes ${ }^{23}$. En otros aspectos, esta tarea es sencillamente imposible y debemos contentarnos con valoraciones cualitativas e «imprecisas». La pérdida de población activa joven, la liquidación de capital humano o lo que Pablo Martín Aceña ha denominado «desquiciamiento institucional», son imposibles de valorar en términos monetarios. No podemos, en definitiva, traducir en un único dato el coste del conflicto. En cualquier caso, es evidente que la guerra no fue tan destructiva como la propaganda franquista se empeñó en sostener durante décadas. Para el fracasado, también en términos económicos, régimen franquista, culpar a los "rojos" del desastre productivo se convirtió en una gran coartada de su propia ineficacia. Todavía en los años sesenta el ministro de Agricultura Cirilo Cánovas agitaba el fantasma del recuerdo de la guerra y las destrucciones de los «rojos», para justificar los problemas de la agricultura española ${ }^{24}$. Un poco de autocrítica, ejercicio impensable en aquel régimen, le hubiera llevado a encontrar las causas de ese fracaso en sus propias actuaciones y, sobre todo, en las de sus antecesores en el cargo durante los años cuarenta. Por otra parte, es innegable que la guerra consumió recursos importantes, como las reservas metálicas del Banco de España y buena parte del ahorro privado, destruido por la guerra o devorado por la inflación, y provocó destrucciones materiales sectorialmente importantes. Sin embargo, en conjunto, no alcanzaron un nivel que podamos calificar como catastrófico. El sector pesquero no sufrió daños; en la agricultura las destrucciones fueron muy limitadas y los grandes cultivos arbóreos, entre ellos el olivar o los cítricos, no sufrieron daño alguno. Las pérdidas de ganado de labor y de renta, con ser más estimables, se situaron en niveles fácilmente recuperables. La minería y la industria, en especial la gran industria vasca, recuperaron su capaci-

23. Un estado de la cuestión en Martín Aceña (2006).

24. Cirilo Cánovas, que desempeñó el cargo entre 1957 y 1965, se refirió muchas veces a la cuestión de las destrucciones bélicas en el sector agrario. Incluso se puede observar que sus valoraciones de los daños fueron en aumento. Mientras en unas declaraciones a la prensa el 27 de abril de 1960 afirmaba que la riqueza agrícola española fue «profundamente afectada en los años 1936 al 1939», en un artículo publicado en el diario ABC, el 1 de octubre de 1961, aseguraba que en 1939 hubo que reconstruir «una economía agraria materialmente arrasada por la contienda». 
dad productiva, y en algunos casos la incrementaron, ya antes de la finalización de la guerra. Existe un cierto acuerdo en señalar el de los transportes como el sector más perjudicado. Sin embargo, los estudiosos del tema han concluido afirmando que las pérdidas en la flota mercante fueron muy pequeñas y que afectaron a buques obsoletos y de escaso tonelaje. En lo que concierne al ferrocarril, el principal medio de transporte interior, se han destacado los daños en las infraestructuras y en el material rodante. No obstante, incluso en este caso, las destrucciones fueron limitadas. Cayón y Muñoz Rubio han concluido sus investigaciones sobre este asunto afirmando que el retraso en la recuperación de las comunicaciones ferroviarias durante los años cuarenta tuvo que ver más con la política autárquica del franquismo que con las destrucciones de la guerra $^{25}$. En conclusión, la información disponible permite afirmar que los daños bélicos, con ser estimables, no alcanzaron proporciones catastróficas, paralizantes de la actividad económica y que impidieran una razonable recuperación. Si nos situamos en este binomio destrucciones-recuperación podemos precisar un poco más lo que estamos señalando. En definitiva, el tiempo necesario para la recuperación es una medida sintética que recoge todos los impactos: los de las destrucciones y pérdidas de cualquier tipo, y los resultantes de la mayor o menor eficacia de las políticas de reconstrucción. Además, como en tantas ocasiones, podemos recurrir a comparaciones internacionales que pueden arrojar mucha luz en el análisis. En este caso, nos puede servir lo acontecido con los países participantes en la Segunda Guerra Mundial. Las destrucciones materiales sufridas por los principales actores en ese conflicto fueron incomparablemente mayores que las padecidas por España. Así, el PIB de 1945 había retrocedido a los niveles de 1886 en Austria, de 1924 en Bélgica, de 1891 en Francia, de 1908 en Alemania, de 1909 en Italia y de 1912 en los Países Bajos. En el caso de España el PIB de 1939 había retrocedido al correspondiente a 1922. Sin embargo, la recuperación económica de estos países fue incomparablemente más rápida. En algunos casos «milagrosamente» rápidas. Austria había recuperado su máximo nivel del PIB de preguerra en 1951, Bélgica en 1948, Francia en 1949, Alemania en 1951, Italia en 1950 y los Países Bajos en 1947. España necesitó 12 años para lograr la recuperación de ese nivel ${ }^{26}$. Un sencillo ejercicio nos permite relacionar el retroceso económico provocado por la guerra, medido en años, con el tiempo, también en años, que fue necesario para lograr la recuperación. Esta relación años de retroceso/años para la recuperación, incluye todos los elementos que in-

25. Cayón García y Muñoz Rubio (2006).

26. Los datos del PiB proceden de Maddison (2001), de Crafts y Toniolo (1996) y de Prados (2003). 
fluyeron tanto en el retraso, como las políticas que posibilitaron la recuperación y bien podríamos denominarla «eficacia relativa en la recuperación respecto a las destrucciones». En el cuadro 1 he presentado los datos correspondientes y un índice en relación a España.

Cuadro 1. Eficacia relativa en la recuperación respecto a las destrucciones

\begin{tabular}{|l|c|c|}
\hline & AÑOS & ÍNDICE (ESPAÑA= 1) \\
\hline AUSTRIA & 9,8 & 6,5 \\
\hline BÉLGICA & 7 & 4,6 \\
\hline FRANCIA & 13,7 & 9,1 \\
\hline ALEMANIA & 6,1 & 4,1 \\
\hline ITALIA & 7,2 & 4,8 \\
\hline PAÍSES BAJOS & 16,5 & 11,0 \\
\hline ESPAÑA & 1,5 & 1 \\
\hline
\end{tabular}

FUENTE: Elaboración propia. Los datos de la columna 1 son el resultado de dividir el número de años que retrocedió el PIB a consecuencia de la guerra, entre el número de años que se tardó en recuperar el nivel máximo de PIB de preguerra.

La interpretación de este índice es muy sencilla, a mayor valor del índice mayor eficacia en la recuperación en relación a las destrucciones. El cuadro muestra que la eficacia en la recuperación europea fue alta (se necesitaron en todos los casos muchos menos años para recuperar las economías, en relación a los años retrocedidos a causa de la guerra). El índice, excluida España, se sitúa en una horquilla entre 4,1 y 11 (ó 1 y 2,6), Alemania, que realizó un gran esfuerzo en la reconstrucción y que aplicó políticas adecuadas, tuvo que hacer frente, sin embargo, a un lastre de destrucciones muy pesado. Lo mismo sucede con Austria y con Italia; por eso, sus índices son peores que los correspondientes al de países menos dañados como Bélgica, o cuya recuperación fue más rápida como los Países Bajos. El caso de España es muy llamativo y excepcional. Su índice 1 significa que los países europeos fueron entre 4 y 11 veces más eficaces que nuestro país en lograr la recuperación económica en relación a las destrucciones. Este índice es tan sólo, en definitiva, una expresión numérica de lo que tantas veces hemos llamado larga y dura posguerra.

Es evidente que si las destrucciones fueron en el caso de España menores y la recuperación exigió mucho más tiempo, las razones hay que buscarlas en otros factores, diferentes a los daños derivados del conflicto. A mi entender, estas causas se encuentran en el carácter del régimen triunfante. Las peores con- 
secuencias de la guerra, en las que la propaganda gubernamental, por razones obvias, no insistió, las sufrió la población española. A los muertos en el conflicto, -muchos de ellos jóvenes en plenitud de su vida laboral-, y en la retaguardia, hay que añadir los cientos de miles de represaliados (fusilados, encarcelados, encuadrados en batallones de castigo, depurados, desterrados y exiliados), represión que se prolongó de forma intensa durante toda la década de los años cuarenta. También durante la guerra se produjeron, al compás del avance de las tropas sublevadas, masivos desplazamientos de la población civil (en torno a dos millones de personas en 1938), lo que resulta del todo inconcebible si no fuera porque sabemos que para los franquistas la Guerra Civil fue una guerra de exterminio. La Ley de Responsabilidades Políticas, y otras normas similares, no tenían por finalidad el cierre de la guerra, sino la continuación de dicho exterminio. Se ha dicho muchas veces que no hubo perdón para los vencidos; un perdón que no resultaba procedente, pues la mayor parte de ellos no tenían culpa alguna por la que tuvieran que ser perdonados. No hubo compasión, no hubo clemencia, no hubo caridad. El deseo de acabar con cualquier vestigio del régimen republicano, de arrancar de raíz el «mal», tuvo unas consecuencias extraordinariamente dañinas sobre la economía española. Muchos de nuestros mejores profesionales, funcionarios, científicos y docentes, particularmente los del cuerpo de maestros, compartían de manera entusiasta los valores democráticos de la República y sufrieron, por ello, una dura represión que, en el peor de los casos, acabó con sus vidas y, en el mejor, con el exilio, la depuración, el destierro o la cárcel. En la obsesión por acabar con la escuela republicana, coincidían todas las fuerzas conservadoras que conformaban el bando franquista y, muy especialmente, la Iglesia católica, ansiosa por empezar a cobrar los réditos de su victoria en la guerra, detentando el monopolio de la enseñanza. Además del enorme sufrimiento, esta desmedida represión provocó una grave pérdida de capital humano, factor fundamental para la recuperación económica y del que España no estaba, precisamente, sobrado. Para colmo de males, muchos de los cargos «vacantes» fueron ocupados por personas fieles al régimen, carentes con frecuencia de la cualificación necesaria (recordemos los aprobados patrióticos y la reserva de puestos para ex-combatientes) y dispuestas a aceptar y a transmitir acríticamente, los más absurdos dogmas y mistificaciones. En definitiva, es en la naturaleza del régimen donde se encuentra, a mi entender, la causa fundamental de este retraso. En España, el final de la guerra no significó, en modo alguno, el comienzo de la paz. Incluso un personaje como Himmler pudo aconsejar a los dirigentes franquistas, de cara a lograr un satisfactorio ritmo de recuperación económica, una política de acercamiento e integración de las clases trabajadoras en el sistema y el fin de la represión. No fue ésta, como bien sabemos, la opción 
del franquismo. Buena muestra del clima reinante es el descenso de las tasas de fecundidad y de natalidad en 1941 y 1942. Contrariamente a lo que suele suceder en una posguerra, en la que la llegada de la paz hace renacer el optimismo, las ganas de vivir y, en consecuencia, los fenómenos conocidos como «baby boom», las sombrías perspectivas que ofrecía la España de Franco provocaron un retraimiento de estos índices demográficos ${ }^{27}$. Por el contrario, en los países europeos se consolidaron, tras la guerra, sistemas políticos basados en valores democráticos avanzados que incluían no sólo derechos políticos, sino también económicos y de protección social. Por otra parte, a pesar de las graves fracturas que se produjeron durante la guerra entre los países europeos, y en el interior de los propios países, que llevaron a procesos posbélicos de depuración de responsabilidades, éstos se cerraron pronto y con una gran generosidad por parte de los vencedores. Los principales países de Europa Occidental tuvieron la fortuna de ser gobernados por partidos democráticos y reformistas que contaron con una excepcional generación de líderes.

Otro elemento fundamental, que explica el atraso en la recuperación de España, hay que buscarlo en los planteamientos económicos del bando vencedor, que se situaban en las antípodas del nuevo modelo de capitalismo, democrático, social y abierto a la cooperación internacional, que se implantó en Europa tras la guerra y que contó con la decisiva ayuda económica norteamericana. El conglomerado que conformaba el bando franquista, con matices de intensidad, repudiaba estos valores europeos. La Iglesia y los tradicionalistas eran, esencialmente, partidarios de sistemas preliberales y aislacionistas. Los militares y Falange eran intervencionistas, estatalistas, neogremialistas, autarquizantes y colonialistas. Todos ellos, incluidos los autoproclamados «revolucionarios», se mostraron de acuerdo en restaurar plenamente el antiguo orden. En el caso de la propiedad de la tierra, las cosas fueron mucho más lejos y se aprovechó la victoria para ejercer la venganza contra los jornaleros partícipes en los procesos de reforma, para el saqueo de los bienes de las colectividades y del Estado y para expulsar a los arrendatarios. Con esta amalgama extravagante de principios caducos y retrógrados, pretendía construir el franquismo un «nuevo modelo de economía», que ignoraba los progresos básicos de la ciencia económica ${ }^{28}$.

27. Ortega Osona y Silvestre Rodríguez (2006).

28. El propio Franco que estaba muy convencido de que sus ideas económicas eran extraordinariamente innovadoras, llegó a afirmar: «Anuncio que la experiencia de nuestra guerra tendrá que influir seriamente en todas las teorías económicas defendidas hasta hace poco como si fueran dogmas». Mientras tanto, como han mostrado Martín Rodríguez y Fernández Clemente (2008), España sufrió un esterilizante exilio de economistas académicos. 
La represión financiera afectó también al sector de los pequeños empresarios que había colaborado con la República. Sin embargo, la medida económica de carácter general más dañina para los perdedores de la guerra fue la unificación monetaria. Los sublevados anularon la validez de todos los billetes republicanos emitidos tras el 18 de julio de 1936 (unos 13.000 millones de pesetas). Se admitieron a la par los billetes emitidos con anterioridad a dicha fecha, siempre y cuando se hubiesen presentado ante las autoridades nacionales para su correspondiente estampillado. Se anularon, igualmente, todas las emisiones autonómicas y locales así como las procedentes de cualquier otro emisor de la zona «roja». En lo concerniente a las obligaciones dinerarias se adoptó el criterio de conceder plena validez a los saldos anteriores al 18 de julio de 1936. Para las posteriores, se procedió a un reconocimiento parcial, que benefició a los empresarios en relación a los particulares y que se realizó conforme a una escala descendente en el tiempo, para compensar la mayor inflación sufrida en la zona leal. Al respecto, Martorell reitera una opinión ya expresada por otros autores en relación a la ley de desbloqueo y afirma que «se encuadra por derecho propio en la panoplia de disposiciones franquistas... de represión económica» ${ }^{29}$.

Hasta finales de los años cuarenta, la mayor parte de los españoles, particularmente los vencidos, los más pobres de ambas zonas (y muy especialmente los de las grandes ciudades republicanas como Madrid y Barcelona), tuvieron que sufrir muy duramente las consecuencias económicas negativas del «experimento» nacional-sindicalista. En el lado contrario, las recuperadas clases dominantes, las élites cercanas al poder y los nuevos ricos nacidos del estraperlo, desvelaban la verdadera cara de los vencedores. Sólo a finales de esa terrible década de hambre y calamidades, cuando se abandonaron las más dañinas de las medidas de intervención y se volvió a recuperar, aunque fuera a regañadientes, la senda de la cooperación económica internacional fue posible el efectivo comienzo de la recuperación.

\section{Fuentes y bibliografía citada}

En los últimos años se han publicado dos obras fundamentales sobre la economía y la Guerra Civil española: la editada por Pablo Martín Aceña y Elena Martínez Ruiz en 2006 y la dirigida por Enrique Fuentes Quintana y coordinada por Francisco Comín en 2008. En ambas se recoge una bibliografía actualizada y exhaustiva. Aquí se recoge exclusivamente la bibliografía citada en el texto. ArChivo DEl IRYDA, Libros de actas del Consejo Nacional de Colonización.

29. Martorell (2006). 
BARCiela, C. (1983), «Producción y política cerealista durante la guerra civil española, 1936-1939», en Anes, G., Rojo, L. A. y Tedde, P. (eds.), Historia Económica y Pensamiento Social, Madrid, Banco de España-Alianza Editorial.

—(1986), «Introducción», en Garrabou, R., Barciela, C. y Jiménez Blanco, J. I. (eds.), Historia agraria de la España contemporánea, vol. 3, El fin de la agricultura tradicional (1900-1960), Barcelona, Crítica.

-(2004), «La propiedad de la tierra durante el franquismo: raíces doctrinales y propuestas de reforma», en Economía y cambio histórico. Estudios en Homenaje a Luis Ángel Rojo, Madrid, Universidad Complutense, vol. II.

Baroja, P. (1985), Juventud. Egolatría, Madrid, Caro Raggio. (Primera edición, 1917).

Berlin, I. (2004), Sobre la libertad, Madrid, Alianza Editorial.

Cabrera, M. y Del Rey, F. (2008), «El cerco a los empresarios. La guerra civil española y sus costes», en Fuentes Quintana, E. (dir.) y Comín, F. (coord.), Economía y economistas españoles en la guerra civil, Madrid, Real Academia de Ciencias Morales y Políticas-Galaxia Gutenberg.

Catalan, J. (2006), «Guerra e industria en las dos Españas, 1936-39», en Martín Aceña, P. y Martínez Ruiz, E. (eds.), La economía de la guerra civil, Madrid, Marcial Pons Historia.

Cayón García, F. y Muñoz Rubio, M. (2006), «Transportes y comunicaciones», en Martín Aceña, P. y Martínez Ruiz, E. (eds.), La economía de la guerra civil, Madrid, Marcial Pons Historia.

Comín, F. (2008), «La hacienda del gobierno de la República española (1936139)», en Fuentes Quintana, E. (dir.) y Comín, F. (coord.), Economía y economistas españoles en la guerra civil, Madrid, Real Academia de Ciencias Morales y Políticas-Galaxia Gutenberg.

Comín, F. y López, S. (2002), «Las dos haciendas públicas y la financiación de la guerra civil», Hacienda Pública Española, Monografía Historia de la Hacienda en el siglo XX.

Crafts, N. y Toniolo, G. (1996), Economic growth in Europe since 1945, Cambridge, Cambridge University Press.

Fuentes Quintana, E. (dir.) y Comín, F. (coord.) (2008), Economía y economistas españoles en la guerra civil, Madrid, Real Academia de Ciencias Morales y Políticas-Galaxia Gutenberg.

Gálvez Muñoz, L. (2006), «Produciendo para la revolución y produciendo para la reacción. Trabajo y guerra civil», en Martín Aceña, P. y Martínez Ruiz, E. (eds.), La economía de la guerra civil, Madrid, Marcial Pons Historia.

Juliá, S. (2008), «En torno a los orígenes de la guerra civil», en Fuentes QuinTANA, E. (dir.) y Comín, F. (coord.), Economía y economistas españoles en la 
guerra civil, Real Academia de Ciencias Morales y Políticas-Galaxia Gutenberg.

Maddison, A. (2001), The World Economy. A Millennial Perspective, París, OECD. Martín Aceña, P. (2001), El oro de Moscú y el oro de Berlín, Madrid, Taurus.

-(2006), «La economía de la guerra civil: perspectiva general y comparada», en Martín Aceña, P. y Martínez Ruiz, E. (eds.), La economía de la guerra civil, Madrid, Marcial Pons Historia.

-(2008), «El Banco de España durante la guerra civil», en Fuentes Quintana, E. (dir.) y Comín, F. (coord.), Economía y economistas españoles en la guerra civil, Madrid, Real Academia de Ciencias Morales y Políticas-Galaxia Gutenberg.

Martín Aceña, P. y Martínez Ruiz, E. (eds.) (2006), La economía de la guerra civil, Madrid, Marcial Pons Historia.

Martín Rodríguez, M. y Fernández Clemente, E. (2008), «Sesenta economistas académicos del exilio (1936-1939)», en Fuentes Quintana, E. (dir.) y Comín, F. (coord.), Economía y economistas españoles en la guerra civil, Madrid, Real Academia de Ciencias Morales y Políticas-Galaxia Gutenberg.

Martínez Ruiz, E. (2006a), «El campo en guerra: organización y producción agraria», en Martín Aceña, P. y Martínez Ruz, E. (eds.), La economía de la guerra civil, Madrid, Marcial Pons Historia.

-(2006b), «Las relaciones económicas internacionales: guerra, política y negocios», en Martín Aceña, P. y Martínez Ruiz, E. (eds.), La economía de la guerra civil, Madrid, Marcial Pons Historia.

Martorell Linares, M. (2006), «Una guerra, dos pesetas», en Martín Aceña, P. y Martínez Ruiz, E. (eds.), La economía de la guerra civil, Madrid, Marcial Pons Historia.

Martorell, M. y Comín, F. (2008), «La Hacienda de guerra franquista», en FuenTEs Quintana, E. (dir.) y Comín, F. (coord.), Economía y economistas españoles en la guerra civil, Madrid, Real Academia de Ciencias Morales y PolíticasGalaxia Gutenberg.

Moradiellos, E. (2008), «El contexto internacional de la guerra civil: entre la intervención y la no intervención», en Fuentes Quintana, E. (dir.) y Comín, F. (coord.), Economía y economistas españoles en la guerra civil, Madrid, Real Academia de Ciencias Morales y Políticas-Galaxia Gutenberg.

Ortega Osona, J. A. y Silvestre Rodríguez, J. (2006), «Las consecuencias demográficas», en Martín Aceña, P. y Martínez Ruiz, E. (eds.), La economía de la guerra civil, Madrid, Marcial Pons Historia.

Pons, M. a Á. (2006), «La Hacienda pública y la financiación de la guerra», en Martín Aceña, P. y Martínez Ruiz, E. (eds.), La economía de la guerra civil, Madrid, Marcial Pons Historia. 
Prados de la Escosura, L. (2003), El progreso económico de España, Bilbao, Fundación BBVA.

SÁncheZ Asiaín, J. Á. (2008), «Guerra monetaria durante la guerra civil», en Fuentes Quintana, E. (dir.) y Comín, F. (coord.), Economía y economistas españoles en la guerra civil, Madrid, Real Academia de Ciencias Morales y PolíticasGalaxia Gutenberg.

Sánchez Recio, G. (1991), La República contra los rebeldes y los desafectos. La represión económica durante la Guerra Civil, Alicante, Universidad de Alicante.

TorRes Villanueva, E. (2006), «Los empresarios: entre la revolución y la colaboración», en Martín AceÑa, P. y Martínez Ruiz, E. (eds.), La economía de la guerra civil, Madrid, Marcial Pons Historia.

Viñas, Á. (2006), La soledad de la República. El abandono de las democracias y el viraje hacia la Unión Soviética, Barcelona, Crítica.

-(2007), El escudo de la República. El oro de España, la apuesta soviética y los hechos de mayo de 1937, Barcelona, Crítica. 